\title{
Influence of comorbidity on hospital outcomes among patients with COVID-19 using electronic records from a nationwide Healthcare System in Peru
}

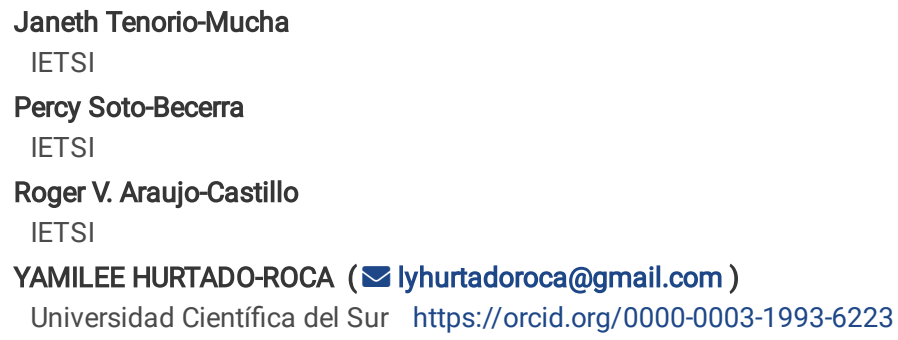

\section{Research Article}

Keywords: comorbidity, covid-19, hospitalization, critical care, mortality

Posted Date: May 11th, 2021

DOI: https://doi.org/10.21203/rs.3.rs-211137/v1

License: () (1) This work is licensed under a Creative Commons Attribution 4.0 International License. Read Full License 


\section{Abstract \\ Background}

Large cases reported that older age and comorbidity are predictors for poor prognosis in COVID-19 patients. Nevertheless, context-specific evidence relevant in low-and middle-income countries is still pending.

\section{Methods}

Retrospective cohort study using electronic health records of confirmed cases admitted in hospitalization areas from the Peruvian Social Health Insurance. The main variable was the presence of comorbidities and the outcomes were in-hospital mortality or intensive care unit admission, and in/out hospital mortality. We used Kaplan-Meier survival curves with the Log-Rank test to compare time-to-event outcomes between comorbidities groups. Crude and adjusted Cox regression models were used to estimate hazard ratios (HR). Statistical analyses were conducted with a significance level of $5 \%$.

\section{Results}

In patients with ICU admission or in-hospital death, $45.99 \%$ had one comorbidity and $50.26 \%$ had two or more comorbidities. Using in/out hospital deaths up to 60 days as the outcome, the overall survival of patients with two comorbidities is lower than patients with one comorbidity, and both are lowest than a patient without comorbidities (Log-rank test $p=0.001$ ). After adjusting for sex, age, severity, and hospital care network patients with one comorbidity (HR: 1.16 ; IC $95 \%$ : 1.04-1.31) and with two or more comorbidities (HR: 1.13; IC 95\%: 1.01-1.26) are at higher risk to die compared with those without comorbidities.

\section{Conclusion}

The presence of comorbidities in hospitalized patients with COVID-19 are risk factors for ICU admission and mortality. Proper identification of these factors can help to identify patients at higher risk in hospital admission and provide specialized care to prevent deaths.

\section{Background}

More than eight months that the World Health Organization (WHO) has declared COVID-19 as a pandemic, millions of people have died because of COVID-19 worldwide with the highest fatality rates reported in males, older adults, and people with comorbidities ${ }^{(1,2)}$. Comorbidities, including hypertension, diabetes, cardiovascular diseases, cerebrovascular disease, chronic obstructive pulmonary disease (COPD), chronic kidney disease, and malignancy, contributed significantly to disease severity, admission to Intensive Care Unit (ICU), acute respiratory distress syndrome (ARDS), invasive ventilation, and death ${ }^{(3)}$.

The disease has spread to almost 200 countries all around the world, but its impact varied among countries, sub-populations, and ethnicities due to biological, cultural, political, and socio-behavioral factors ${ }^{(4)}$. In the early months of the pandemic, most research about cases and deaths were reported in China, Italy, France, and the United States leaving uncertainty about the impact of the disease in low-and middle-income countries ${ }^{(5)}$. A special uncertainty arises in Latin American countries because of the lack of preparedness for the pandemic, the lack of capacity for testing, the insufficient amount of ventilator, high rates of non-communicable diseases, the building capacity of the health systems, the coexistence of other outbreaks as dengue, but also lack of leadership of some of their presidents ${ }^{(6)}$.

Peru is a Latin American country, which reported its first case of COVID-19 on March 6, 2020; since then Peru was one of the countries with the strictest measures in our region including school and borders closures, the declaration of a national emergency with social distancing, and even the implementation of a curfew. Regarding health issues, Peru dictated measures to ensure the supply of essential health goods, and establish all the public, private, or mixed sanitary entities were under the direction of the Ministry of Health to guarantee health access ${ }^{(7)}$. Although these measures, for the second week of October, Peru ranks 3th worldwide in the confirmed COVID-19 deaths per million people ${ }^{(8)}$.

Large cases reported that older age and comorbidity are predictors for poor prognosis in COVID-19 patients ${ }^{(3,9,10)}$. Nevertheless, context-specific evidence relevant to low-and middle-income countries is still pending. Understanding the impact and consequences of current COVID-19 may help decision-makers and governments to improve and adjust efforts in real-time. Particularly, Latin American countries need to use results from their first months of the pandemic to settle their strategies to be prepared for a possible second wave of cases. Thus, this study aims to assess the risk of ICU admission and death in hospitalized patients according to the presence and types of comorbidities in hospitals from the Peruvian Social Health Insurance.

\section{Methods}

\subsection{Study design and population}

Retrospective cohort study using electronic health records from mid-and high-level care hospitals that belong to the Peruvian Social Health Insurance. Peru has a fragmented health system including public and private health institutions, the Peruvian Social Health Insurance is the second largest public health provider, which insured all the formal employed population and their families ${ }^{(11)}$. We include all patients who met the following criteria: 18 years or above 
subjects; confirmed SARS-CoV-2 infection; admitted in hospitalization areas between April 1 and July 19, 2020. We excluded patients hospitalized in COVID-19 Villages, a national strategy that hospitalized asymptomatic SARS-CoV-2 patients only for isolation and control of the spread of the epidemic.

\subsection{Variables}

From the electronic health record, we collected data about sex, age, weight, body mass index (BMI). Then we categorized age between 18-39 years, 40-59 years, and 60 years or more, and BMI was divided under $25 \mathrm{~kg} / \mathrm{m} 2,25 \mathrm{~kg} / \mathrm{m} 2-29.9 \mathrm{~kg} / \mathrm{m} 2$, and $30 \mathrm{~kg} / \mathrm{m} 2$ or more. The administrative division of the Peruvian Social Health Insurance includes 34 care networks all around the country; for this study, we grouped them into four categories. We consider the three main care networks Almenara, Rebagliati, and Sabogal located in Lima (capital of Peru), Piura as the city with the most reported cases outside the capital during the study period, and the other 30 care networks grouped all together. The severity variable was built if severe acute respiratory syndrome, respiratory insufficiency, sepsis, or pulmonary edema were present in the first 24 hours of hospitalization; the presence of at least one of these conditions was considered as a lifethreatening illness.

To generate comorbidity variables, we relied on previously grouped lists of diagnosis codes (based on International Classification of Diseases codes, 10 th revision) named comorbidity maps ${ }^{(12)}$. We used the comorbidity map proposed by Elixhauser, which coded 31 different comorbidities using diagnosis wrote by a physician in the electronic health records ${ }^{(13,14)}$. Then we group congestive heart failure, cardiac arrhythmias, valvular disease, peripheral vascular disorders, and coagulopathy as cardiovascular diseases; hypertension uncomplicated and complicated, were considered together just like hypertension, and the same for diabetes uncomplicated and complicated, considered just as diabetes; in neoplasia category, we considered neoplasia itself, lymphoma, metastatic cancer, and solid tumor without metastasis. We keep the following comorbidities for this study: obesity, cardiovascular diseases, hypertension, diabetes, chronic kidney disease, chronic pulmonary disease, neoplasia, liver disease, and rheumatic disease. For further analysis, we consider a variable for the number of comorbidities categorized as without comorbidities, one comorbidity, and two or more comorbidities. The primary endpoint was all caused mortality occurred in or out hospitalization, the secondary endpoint was ICU admission or in-hospital mortality, whichever occurred first. Each individual has 60 days of follow-up.

\subsection{Data management}

We retrieved anonymized data obtained from patients hospitalized with COVID-19 which were routinely registered in electronic health records in mid-and highlevel complexity hospitals from the Peruvian Social Security Health System ${ }^{(15)}$. Data were processed using the package data.table ${ }^{(16)}$ for large datasets and functions of dplyr ${ }^{(17)}$, both in R version 4.02 for MS Windows Pro $10 \times 64$ bits.

\subsection{Statistical methods}

We described sociodemographic and clinical characteristics of all patients (discharged, with ICU admission, or death) as medians and interquartile range [IQR] for numeric variables and as proportions for categorical variables. Differences between patients by the number of comorbidities (without comorbidities, one comorbidity, and two or more comorbidities) were assessed using the chi2 test for categorical variables and the non-parametric Kruskal-Wallis test for medians. We performed a time to event analysis for mortality at any point of the follow-up (in/out hospital) and in-hospital mortality or ICU-admission. The onset of follow-up for each patient was the date of hospitalization and the end of the follow-up was the date of occurrence of death, the elapsed time of 60 days, or the end of follow-up by July 19, 2020, whichever happened first. We used Kaplan-Meier survival curves with the Log-Rank test to compare time-toevent outcomes between groups. Crude and adjusted Cox regression models were used to estimate hazard ratios (HR) for time-to-event, using cluster variance estimation, each health center defining a cluster. The multivariate Cox regressions evaluated the number of comorbidities adjusted by sex, age, severity, and hospital care network. Statistical analyses were conducted using Stata software (version 16.0, StataCorp LLC, College Station, TX, USA) with a significance level of $5 \%$.

\subsection{Ethics}

This study was classified as a minimal risk for participants. To maintain the privacy of the patients, the informatics office anonymized all datasets before transfer to researchers. The study protocol was approved by the Institutional Review Board of COVID studies (91-SGRyGISDIS-IETSI-ESSALUD-2020) and was also registered in the Peruvian Health Research Projects repository (PRISA, by its acronym in Spanish) ID number 1353(18).

\section{Results}

\subsection{Sociodemographic and clinical characteristics}

Hospitals from the Peruvian Social Health Insurance attend 15,557 hospitalized patients with confirmed COVID-19 between April 1 and July 19,2020 , of whom $4,444(28.6 \%)$ have one comorbidity, and 3,088 (19.8\%) two or more comorbidities. Overall, $66.75 \%$ of the confirmed cases were male and the median age was 60.3 (IQR: 22.7) with 50.65\% equal or above 60 years old. The median BMI was 28.7 (IQR: 6.3) and $81.03 \%$ of the patients were overweight or obese. Table 1 shows sociodemographic and clinical characteristics by the number of comorbidities. The proportion of males are higher in all the groups by the number of comorbidities. The median age for patients with two or more comorbidities is 65.7 (IQR: 17.5), with one comorbidity is 62.6 (IQR: 21.1 ), and without comorbidities is 56.1 (IQR: 24.9).

Overall, the proportion of comorbidities were hypertension (24.80\%), diabetes (19.26\%), obesity (12.48 \%), chronic kidney disease (6.95\%), cardiovascular diseases (5.16\%), pulmonary disease (3.41\%), neoplasia (1.92\%), liver disease (1.05\%), and rheumatic disease (0.86\%). In the age group of 60 years or more, $56.17 \%$ had one comorbidity and $67.03 \%$ had two or more comorbidities. Patients with comorbidities are more likely to have a worst progression of the disease, in patients with ICU admission or in-hospital death $45.99 \%$ had one comorbidity and $50.26 \%$ had two or more comorbidities. Table 2 shows characteristics between discharge, ICU admission, and death groups. 


\subsection{Risk to ICU admission or in-hospital mortality}

The Kaplan-Meier survival curves for ICU admission or in-hospital mortality shows that having comorbidities (Fig. 1). Table 3 shows Cox regression for ICU admission or in-hospital mortality. Patients with two or more comorbidities are more likely to progress to ICU admission or death compared with those without comorbidities $(\mathrm{p}<0.05)$. The presence of obesity, hypertension, diabetes, and chronic kidney disease was significantly associated with an increased likelihood of either, ICU admission or death. After adjusting for sex, age, severity, and hospital care network patients with one comorbidity (HR: 1.09; IC 95 \%: 1.01-1.18) were at higher risk to ICU admission compared with those without comorbidities. Other variables that showed to increase the risk of ICU admission or death are male sex, age, and hospital care network.

\subsection{Risk to ICU in/out hospital mortality}

Using in/out hospital deaths up to 60 days as the outcome, the Kaplan-Meier survival curves (Fig. 2) showed that the overall survival of patients with two comorbidities is lower than patients with one comorbidity, and both are lowest than a patient without comorbidities (Log-rank test $p=0.001)$. In a Cox regression, the presence of cardiovascular diseases, hypertension, diabetes, chronic kidney disease, neoplasia, and liver disease is associated with a higher risk of mortality. After adjusting for sex, age, severity, and hospital care network patients with one comorbidity (HR: 1.16; IC 95\%: 1.04-1.31) and with two or more comorbidities (HR: 1.13; IC 95\%: 1.01-1.26) are at higher risk to die compared with those without comorbidities.

\section{Discussion}

Comorbidities, including obesity, cardiovascular diseases, hypertension, diabetes, chronic kidney disease, and neoplasia contributed significantly to ICU admission or death in hospitalized patients with confirmed COVID-19. Having two or more comorbidities concomitantly increased the risk of ICU admission by $57 \%$ and to death by $31 \%$ compared with those without comorbidities. Male sex, older age, and comorbidities have consistently shown a higher risk of mortality, but we also found that the hospital care network contributed to adverse outcomes.

The relationship between underlying diseases and the severity of COVID-19 is explained by different pathophysiology mechanisms. It has been stated the influence of inflammatory processes with the accumulation of immune response cells in metabolic tissues ${ }^{(19,20)}$, the deterioration of lymphocyte and macrophage function ${ }^{(21)}$, the renin-angiotensin-aldosterone system imbalance ${ }^{(22)}$, and more recently, processes of hyper-inflammation and detrimental immunothrombosis ${ }^{(23)}$. Therefore, people with chronic conditions must take extra precautions to avoid COVID-19 infection.

The results of this study are similar to those published in China ${ }^{(24)}$, the United States ${ }^{(25,26)}$, Spain ${ }^{(15)}$, and Mexico(27). In China(24) the most prevalent underlying diseases in hospitalized patients were hypertension (16.4\%), cardiovascular diseases (12.1\%), and diabetes (7.9\%). In the United States ${ }^{(25)}$, instead, the proportion was higher, for hypertension (63.7\%) and diabetes (38.4\%). In comparison, our results, the most prevalent comorbidities were hypertension $24.8 \%$, diabetes $19.3 \%$, and obesity $12.5 \%$. By the number of comorbidities, our proportions of the groups with one comorbidity and with two or more comorbidities are similar to those reported in Mexico, $26.0 \%$ and $19.3 \%$, respectively.

In Peru, non-communicable diseases such as neoplasm, cardiovascular diseases, diabetes, and chronic kidney disease rank at the top causes of death and contributed significantly to the burden of disease ${ }^{(31)}$. Even though the different efforts implementing policies for the management of chronic diseases such as the "Plan Esperanza" for cancer ${ }^{(32)}$ or the HEARTS initiative for cardiovascular diseases ${ }^{(33)}$, Peru has challenges to accomplish health international goals ${ }^{(34)}$. The individual itself and the health system share responsibilities for the poor control of chronic diseases. On the individual's side, there is low awareness, adherence to treatment, and control ${ }^{(35)}$. On the health system's side, we found low political commitment, insufficient financial and human resources, as well as, barriers to access to medicine and regular appointments ${ }^{(36)}$. Although in our study we did not have information about the status of treatment or control of chronic diseases to associate them with worse prognosis, it is known that patients with uncontrolled hypertension or cardiovascular diseases may induce more complications in patients with COVID-19(37).

\subsection{Relevance on public health}

The first cases of COVID-19 in Peru were reported in March after four months of the first cases in China. During January and February, the WHO warned countries must be prepared for a possible pandemic ${ }^{(38)}$. Peru could not be prepared timely because of past and recent health decisions of government and stakeholders, and the high mortality rate had a significant component of disobedience of restrictions by the population ${ }^{(39)}$. As describe above different measures are taken to face COVID-19 but more efforts are needed for vulnerable people as the elderly or with comorbidities. Many health resources including personnel, infrastructure, medicines, and budgets have been centralized on COVID-19 neglecting healthcare for people with underlying diseases. People with chronic diseases need access to treatments for proper control of their condition, the lack of attention and provision of medicines generates complications that can predispose to worse endpoints if they also acquire COVID-19. The COVID-19 pandemic will continue to be a problem in countries and until an effective cure or safe vaccine is found, it is a function of the health system to take decisions under their control and drive preventive actions tackling underlying disease instead of just COVID-19 management.

\subsection{Limitations}

We recognized some limitations of this study; our study design only allows describing risk factors related to comorbidities and ICU admission or mortality and serves to identify populations and characteristics that predispose to negative prognosis, we cannot establish causality. The results of this study cannot be generalized to the entire population with confirmed COVID-19 since the results only correspond to hospitalized patients. Even though electronic health records have information about clinical variables at admission, we did not include them in our result because of important proportions of missing; weight (66.9\%), blood pressure (60\%), body temperature (65\%), oxygen saturation (96\%), heart rate (51\%), and breath rate $(61.4 \%)$. Those missing may indicate lack of 
measurement or lack of report due to scarcity of human resources or high demand of patients, either way, it is important not to neglect these measurements because they may help to proper diagnosis and treatment. In some cases, the errors in patients' evaluation at admission may be differential by severity, where patients with obvious warning symptoms and signs were considered with a life-threatening illness, avoiding clinical measures, but providing prompt healthcare. We stratified patient's characteristics by severity and adjusted Cox regression by this variable.

On the other hand, the main strength of this study is the inclusion of nationwide data that convey a wider picture concerning patients affiliated with Peruvian Social Health Insurance. Another important strength is we defined comorbidities based on the International Classification of Diseases at any point of the hospitalization, which provides a more reliable identification of the disease and reduces the risk of underestimation caused by self-report. In addition to that, we have a follow-up period that best describes the impact of COVID-19 at the beginning of the pandemic in Peru.

\section{Conclusion}

The presence of comorbidities in hospitalized patients with COVID-19 is a risk factor for ICU admission and mortality, particularly obesity, cardiovascular diseases, hypertension, diabetes, and chronic kidney disease. Also, those negative outcomes are influenced by male sex and older age. Proper identification of these factors can help to identify patients at higher risk in hospital admission and provide specialized care to prevent deaths.

\section{Declarations}

\section{Funding:}

This study was funded by the Instituto de Evaluación de Tecnologías en Salud e Investigación - IETSI, EsSalud - Peru.

\section{Conflicts of interest:}

The authors declare no conflicts of interest regarding the subject of this scientific article.

\section{Ethical approval:}

The study protocol was approved by the Institutional Review Board of COVID studies (91-SGRyGISDIS-IETSI-ESSALUD-2020)

\section{Author's contribution:}

JTM was responsible of data analysis and their interpretation, and writing of the first and subsequent drafts of the paper. RAC and PSB checked data analysis and provide feedback in the writing. YHR provide methodological support and participate in the writing of the final version of the paper. All the authors are responsible for the content of this manuscript.

\section{References}

1. Yang X, Yu Y, Xu J, Shu H, Xia A, Liu H, et al. Clinical course and outcomes of critically ill patients with SARS-CoV-2 pneumonia in Wuhan, China: a singlecentered, retrospective, observational study. Lancet Respir Med. 2020;

2. Guan W, Liang W, Zhao Y, Liang H, Chen Z, Li Y, et al. Comorbidity and its impact on 1590 patients with Covid-19 in China: A Nationwide Analysis. Eur Respir J. 2020;

3. Fang X, Li S, Yu H, Wang P, Zhang Y, Chen Z, et al. Epidemiological, comorbidity factors with severity and prognosis of COVID-19: A systematic review and meta-analysis. Aging (Albany NY). 2020;12(13):12493-503.

4. Pareek M, Bangash MN, Pareek N, Pan D, Sze S, Minhas JS, et al. Ethnicity and COVID-19: an urgent public health research priority. Vol. 395, The Lancet. Lancet Publishing Group; 2020. p. 1421-2.

5. Gupta M, Wahl B, Adhikari B, Bar-Zeev N, Bhandari S, Coria A, et al. The need for COVID-19 research in low- and middle-income countries. Glob Heal Res Policy. 2020;5(1)

6. Burki T. COVID-19 in Latin America. Lancet Infect Dis. 2020 May 1;20(5):547-8.

7. El Peruano - Decreto Supremo que declara Estado de Emergencia Nacional por las graves circunstancias que afectan la vida de la Nación a consecuencia del brote del COVID-19 - DECRETO SUPREMO - № 044-2020-PCM - PODER EJECUTIVO - PRESIDENCIA DEL CONSEJO DE MINISTROS [Internet]. [cited 2020 Oct 10]. Available from: https://busquedas.elperuano.pe/normaslegales/decreto-supremo-que-declara-estado-de-emergencia-nacional-po-decretosupremo-n-044-2020-pcm-1864948-2/

8. Coronavirus Pandemic Data Explorer - Our World in Data [Internet]. [cited 2020 Oct 10]. Available from: https://ourworldindata.org/coronavirus-dataexplorer?zoomToSelection=true\&time=2020-03-

01..latest\&country=MEX IND USA ITA BRA GBR FRA ESP PER\&region=World\&casesMetric=true\&interval=smoothed\&perCapita=true\&smoothing=7.

9. Wang B, Li R, Lu Z, Huang Y. Does comorbidity increase the risk of patients with covid-19: Evidence from meta-analysis. Aging (Albany NY). 2020 Apr 1;12(7):6049-57.

10. Sanyaolu A, Okorie C, Marinkovic A, Patidar R, Younis K, Desai P, et al. Comorbidity and its Impact on Patients with COVID-19. SN Compr Clin Med. 2020 Aug;2(8):1069-76.

11. Alcalde-Rabanal J, Lazo-Gonzales O, Nigenda G. Sistema de salud de Perú. Salud Publica Mex. 2011;53(2):243-54.

12. Elixhauser A, Steiner C, Harris DR, Coffey RM. Comorbidity Measures for Use with Administrative Data. Med Care. 1998;36(1):8-27. 
13. Quan H, Sundararajan V, Halfon P, Fong A, Burnand B, Luthi J-C, et al. Coding Algorithms for Defining Comorbidities in ICD-9-CM and ICD-10 Administrative Data. 2005.

14. Metcalfe D, Masters J, Delmestri A, Judge A, Perry D, Zogg C, et al. Coding algorithms for defining Charlson and Elixhauser co-morbidities in Read-coded databases. BMC Med Res Methodol. 2019 Jun 6;19(1):115.

15. Poblador-Plou B, Carmona-Pírez J, loakeim-Skoufa I, Poncel-Falcó A, Bliek-Bueno K, Cano-Del Pozo M, et al. Baseline chronic comorbidity and mortality in laboratory-confirmed COVID-19 cases: Results from the PRECOVID study in Spain. Int J Environ Res Public Health. 2020 Jul 2;17(14):1-14.

16. (No Title) [Internet]. [cited 2020 Oct 24]. Available from: https://cran.r-project.org/web/packages/data.table/data.table.pdf

17. (No Title) [Internet]. [cited 2020 Oct 24]. Available from: https://cran.r-project.org/web/packages/dplyr/dplyr.pdf

18. PRISA | Multimorbilidad y progresión a enfermedad severa y mortalidad por SARS-CoV-2 en pacientes hospitalizados por COVID-19 [Internet]. [cited 2020 Oct 11]. Available from: https://prisa.ins.gob.pe/index.php/acerca-de-prisa/busqueda-de-proyectos-de-investigacion-en-salud/1196-multimorbilidad-yprogresion-a-enfermedad-severa-y-mortalidad-por-sars-cov-2-en-pacientes-hospitalizados-por-covid-19

19. Bansal R, Gubbi S, Muniyappa R. Metabolic syndrome and COVID 19: Endocrine-immune-vascular interactions shapes clinical course. Vol. 161, Endocrinology (United States). Endocrine Society; 2020. p. 20892-1613.

20. Korakas E, Ikonomidis I, Kousathana F, Balampanis K, Kountouri A, Raptis A, et al. Obesity and COVID-19: Immune and metabolic derangement as a possible link to adverse clinical outcomes. Vol. 319, American Journal of Physiology - Endocrinology and Metabolism. American Physiological Society; 2020. p. E105-9.

21. García LF. Immune Response, Inflammation, and the Clinical Spectrum of COVID-19. Vol. 11, Frontiers in Immunology. Frontiers Media S.A.; 2020. p. 1441.

22. Alexandre J, Cracowski JL, Richard V, Bouhanick B. Renin-angiotensin-aldosterone system and COVID-19 infection. Ann Endocrinol (Paris). 2020 Jun 1;81(2-3):63-7.

23. Henry BM, Vikse J, Benoit S, Favaloro EJ, Lippi G. Hyperinflammation and derangement of renin-angiotensin-aldosterone system in COVID-19: A novel hypothesis for clinically suspected hypercoagulopathy and microvascular immunothrombosis. Vol. 507, Clinica Chimica Acta. Elsevier B.V.; 2020. p. 16773.

24. Emami A, Javanmardi F, Pirbonyeh N, Akbari A. Prevalence of Underlying Diseases in Hospitalized Patients with COVID-19: a Systematic Review and Meta-Analysis. Vol. 8, Archives of Academic Emergency Medicine. 2020.

25. Suleyman G, Fadel RA, Malette KM, Hammond C, Abdulla H, Entz A, et al. Clinical Characteristics and Morbidity Associated With Coronavirus Disease 2019 in a Series of Patients in Metropolitan Detroit. JAMA Netw open. 2020 Jun 1;3(6):e2012270.

26. Mani VR, Kalabin A, Valdivieso SC, Murray-Ramcharan M, Donaldson B. New York Inner City Hospital CoVID-19 Experience and Current Data: Retrospective Analysis at the Epicenter of the American Coronavirus Outbreak. J Med Internet Res. 2020 Sep 18;22(9):e20548.

27. Kammar-García A, Vidal-Mayo J de J, Vera-Zertuche JM, Lazcano-Hernández M, Vera-López O, Segura-Badilla 0, et al. Impact of comorbidities in mexican SARS-CoV-2 positive patients: a retrospective analysis in a national cohort. Rev Investig Clin. 2020;72(3):151-8.

28. Guan W-J, Ni Z-Y, Hu Y, Liang W-H, Ou C-Q, He J-X, et al. Clinical Characteristics of Coronavirus Disease 2019 in China. N Engl J Med. 2020 Feb;

29. Wang D, Hu B, Hu C, Zhu F, Liu X, Zhang J, et al. Clinical Characteristics of 138 Hospitalized Patients With 2019 Novel Coronavirus-Infected Pneumonia in Wuhan, China. JAMA. 2020 Feb;

30. Zhou F, Yu T, Du R, Fan G, Liu Y, Liu Z, et al. Clinical course and risk factors for mortality of adult inpatients with COVID-19 in Wuhan, China: a retrospective cohort study. Lancet. 2020;395:1054-62.

31. Nickel $\mathrm{CH}$, Rueegg M, Pargger H, Bingisser R. Age, comorbidity, frailty status: effects on disposition and resource allocation during the COVID-19 pandemic. Swiss Med Wkly. 2020 Apr 20;150(1718):w20269.

32. Vidaurre T, Santos C, Gómez H, Sarria G, Amorin E, López M, et al. The implementation of the Plan Esperanza and response to the imPACT Review. Lancet Oncol. 2017;18(10):e595-606.

33. OPS/OMS Perú - Lanzamiento HEARTS Perú: la iniciativa mundial más importante para la prevención y el control de las enfermedades cardiovasculares llega a nuestro país. [Internet]. [cited 2020 Oct 15]. Available from: https://www.paho.org/per/index.php?

option=com_content\&view=article\&id=4363:Ianzamiento-hearts-peru-la-iniciativa-mundial-mas-importante-para-la-prevencion-y-el-control-de-lasenfermedades-cardiovasculares-llega-a-nuestro-pais\&ltemid=1062

34. Carrillo-Larco RM, Bennett JE, Cesare M Di, Gregg EW, Bernabe-Ortiz Id A. The contribution of specific non-communicable diseases to the achievement of the Sustainable Development Goal 3.4 in Peru. 2020;

35. Villarreal-Zegarra D, Carrillo-Larco RM, Bernabe-Ortiz A. Short-term trends in the prevalence, awareness, treatment, and control of arterial hypertension in Peru. J Hum Hypertens. 2020 Jun 9;1-10.

36. Cardenas MK, Miranda JJ, Beran D. Delivery of Type 2 diabetes care in low- and middle-income countries: lessons from Lima, Peru. Diabet Med. 2016 Jun;33(6):752-60.

37. Tadic M, Cuspidi C, Mancia G, Dell'Oro R, Grassi G. COVID-19, hypertension and cardiovascular diseases: Should we change the therapy? Vol. 158, Pharmacological Research. Academic Press; 2020.

38. WHO Director-General's opening remarks at the media briefing on COVID-19 - 24 February 2020 [Internet]. [cited 2020 Oct 16]. Available from: https://www.who.int/dg/speeches/detail/who-director-general-s-opening-remarks-at-the-media-briefing-on-covid-19--24-february-2020

39. Coronavirus en Perú: 5 factores que explican por qué es el país con la mayor tasa de mortalidad entre los más afectados por la pandemia - BBC News Mundo [Internet]. [cited 2020 Oct 16]. Available from: https://www.bbc.com/mundo/noticias-america-latina-53940042 
Table 1. Demographic and clinical characteristics of patients hospitalized with confirmed COVID-19 stratified by the number of comorbidities.

\begin{tabular}{|c|c|c|c|c|c|}
\hline Variables & Total & $\begin{array}{c}\text { Without } \\
\text { comorbidities }\end{array}$ & $\begin{array}{c}\text { One } \\
\text { comorbidity }\end{array}$ & \multirow{2}{*}{$\begin{array}{c}\begin{array}{l}\text { Two or more } \\
\text { comorbidities }\end{array} \\
\mathrm{n}=3088(19.8 \%) \\
\end{array}$} & \multirow[t]{2}{*}{ p-value ** } \\
\hline \multicolumn{4}{|l|}{ Sociodemographic variables } & & \\
\hline \multicolumn{6}{|l|}{ Sex } \\
\hline Female & $517333.25 \%$ & $247230.80 \%$ & $144732.56 \%$ & $125440.61 \%$ & 0.001 \\
\hline Male & $1038466.75 \%$ & $555369.20 \%$ & $299767.44 \%$ & $183459.39 \%$ & \\
\hline Age & $60.3(22.7) *$ & 56.1 (24.9)* & $62.6(21.1)^{*}$ & $65.7(17.5)^{*}$ & $0.001 * * *$ \\
\hline 18 - 39 years & $2017 \quad 12.97 \%$ & $152819.04 \%$ & $3618.12 \%$ & $1284.15 \%$ & 0.001 \\
\hline $40-59$ years & $566136.39 \%$ & $318439.68 \%$ & $158735.71 \%$ & $890 \quad 28.82 \%$ & \\
\hline$\geq 60$ years & $787950.65 \%$ & $331341.28 \%$ & $249656.17 \%$ & $207067.03 \%$ & \\
\hline Body Mass Index $(\mathrm{Kg} / \mathrm{m} 2)(\mathrm{n}=2731)$ & $28.7(6.3)^{*}$ & $28.1(5.5)^{*}$ & $29.1(6.4)^{*}$ & $30.1(7.3)^{*}$ & $0.001 * * *$ \\
\hline$<25 \mathrm{~kg} / \mathrm{m} 2$ & $518 \quad 18.97 \%$ & $271 \quad 19.40 \%$ & $147 \quad 19.34 \%$ & $100 \quad 17.42 \%$ & 0.001 \\
\hline $25-29.9 \mathrm{~kg} / \mathrm{m} 2$ & $112541.19 \%$ & $65246.67 \%$ & $29338.55 \%$ & $18031.36 \%$ & \\
\hline$\geq 30 \mathrm{~kg} / \mathrm{m} 2$ & $1088 \quad 39.84 \%$ & $47433.93 \%$ & $320 \quad 42.11 \%$ & $29451.22 \%$ & \\
\hline \multicolumn{6}{|l|}{ Severity } \\
\hline Non-life threatening illness & $1236079.45 \%$ & $6650 \quad 82.87 \%$ & $339376.35 \%$ & $231775.03 \%$ & 0.001 \\
\hline Life-threatening illness & $3197 \quad 20.55 \%$ & $137517.13 \%$ & $105123.65 \%$ & $77124.97 \%$ & \\
\hline \multicolumn{6}{|l|}{ Progression of the disease } \\
\hline ICU admission & $4623 \quad 29.72 \%$ & $2070 \quad 25.79 \%$ & $146132.88 \%$ & $109235.36 \%$ & 0.001 \\
\hline SARS & $2262 \quad 14.54 \%$ & $81810.19 \%$ & $764 \quad 17.19 \%$ & $680 \quad 22.02 \%$ & 0.001 \\
\hline In-hospital Death & $3896 \quad 25.04 \%$ & $168320.97 \%$ & $1258 \quad 28.31 \%$ & $955 \quad 30.93 \%$ & 0.001 \\
\hline ICU admission or In-hospital Death & $6507 \quad 41.83 \%$ & $291136.27 \%$ & $2044 \quad 45.99 \%$ & $155250.26 \%$ & 0.001 \\
\hline
\end{tabular}

For categorical variables, absolute frequency (n) and percentage in columns (\%) are reported

* For numerical variables, median (interquartile range) is reported

** p-value was assessed using chi2 for categorical variables

*** p-value was assessed using the non-parametric Kruskal Wallis test for numerical variables

Table 2. Demographic and clinical characteristics of patients hospitalized with confirmed COVID-19.

\begin{tabular}{|c|c|c|c|c|c|}
\hline \multirow[t]{2}{*}{ Variables } & \multirow{2}{*}{$\begin{array}{c}\text { Discharge } \\
\mathrm{n}=11661(75.0 \%)\end{array}$} & \multicolumn{2}{|c|}{ In-Hospital Death } & \multicolumn{2}{|c|}{ In-Hospital Death or ICU admission } \\
\hline & & $\mathrm{n}=3896(25.0 \%)$ & p-value $* *$ & $\mathrm{n}=6507(41.8 \%)$ & p-value ** \\
\hline \multicolumn{6}{|l|}{ Sociodemographic variables } \\
\hline \multicolumn{6}{|l|}{ Sex } \\
\hline Female & $410079.26 \%$ & $107320.74 \%$ & 0.001 & $179434.68 \%$ & 0.001 \\
\hline Male & $756172.81 \%$ & $282327.19 \%$ & & $471345.39 \%$ & \\
\hline Age & $57.0(22.7)^{*}$ & $69.1(17.4)^{*}$ & $0.001 * * *$ & $65.0(19.9)^{*}$ & $0.001 * * *$ \\
\hline 18 - 39 years & $192995.64 \%$ & $884.36 \%$ & 0.001 & $390 \quad 19.34 \%$ & 0.001 \\
\hline $40-59$ years & $478384.49 \%$ & $878 \quad 15.51 \%$ & & $203535.95 \%$ & \\
\hline$\geq 60$ years & $494962.81 \%$ & $293037.19 \%$ & & $408251.81 \%$ & \\
\hline \multicolumn{6}{|l|}{ Severity } \\
\hline Non-life threatening illness & $943576.33 \%$ & $292523.67 \%$ & 0.001 & $5030 \quad 40.70 \%$ & 0.001 \\
\hline Life-threatening illness & $2226 \quad 69.63 \%$ & $94130.37 \%$ & & $147746.20 \%$ & \\
\hline \multicolumn{6}{|l|}{ Number of comorbidities } \\
\hline Without comorbidities & $634279.03 \%$ & $168320.97 \%$ & 0.001 & $291136.27 \%$ & 0.001 \\
\hline 1 comorbidity & $318671.69 \%$ & $1258 \quad 28.31 \%$ & & $2044 \quad 45.99 \%$ & \\
\hline 2 or more comorbidities & $213369.07 \%$ & $95530.93 \%$ & & $155250.26 \%$ & \\
\hline \multicolumn{6}{|l|}{ Type of comorbidities } \\
\hline Obesity & $142673.47 \%$ & $51526.53 \%$ & 0.105 & $100351.67 \%$ & 0.001 \\
\hline Cardiovascular diseases & $540 \quad 67.33 \%$ & $26232.67 \%$ & 0.001 & $42853.37 \%$ & 0.001 \\
\hline Hypertension & $265568.82 \%$ & $120331.18 \%$ & 0.001 & $186248.26 \%$ & 0.001 \\
\hline Diabetes & $219973.40 \%$ & $797 \quad 26.60 \%$ & 0.028 & $133944.69 \%$ & 0.001 \\
\hline Chronic kidney disease & $63558.74 \%$ & $446 \quad 41.26 \%$ & 0.001 & $61957.26 \%$ & 0.001 \\
\hline Pulmonary disease & $396 \quad 74.72 \%$ & $13425.28 \%$ & 0.897 & $250 \quad 47.17 \%$ & 0.011 \\
\hline Neoplasia & $19063.55 \%$ & $10936.45 \%$ & 0.001 & $15551.84 \%$ & 0.001 \\
\hline Liver disease & $10564.02 \%$ & $5935.98 \%$ & 0.001 & $8048.78 \%$ & 0.070 \\
\hline Rheumatic disease & $9873.13 \%$ & $36 \quad 26.87 \%$ & 0.625 & $6750.00 \%$ & 0.054 \\
\hline
\end{tabular}

In-Hospital Death and ICU admission are not mutually exclusive.

For categorical variables, absolute frequency (n) and percentage in rows (\%) are reported.

* For numerical variables, median (interquartile range) is reported

** p-value was assessed using chi2 for categorical variables, $* * *$ p-value was assessed using the non-parametric Kruskal Wallis test for numerical variables

Table 3. Crude and Adjusted Cox regression for in-hospital mortality or ICU admission in patients hospitalized with confirmed COVID-19. 


\begin{tabular}{|c|c|c|c|c|c|c|}
\hline \multirow[t]{2}{*}{ Variables } & \multicolumn{3}{|c|}{ Crude* } & \multicolumn{3}{|c|}{ Adjusted** } \\
\hline & cHR & $95 \% \mathrm{CI}$ & p-value & aHR & $95 \% \mathrm{CI}$ & p-value \\
\hline \multicolumn{7}{|l|}{ Sociodemographic variables } \\
\hline \multicolumn{7}{|l|}{ Sex } \\
\hline Female & Ref. & & & Ref. & & \\
\hline Male & 1.24 & $(1.10-1.39)$ & 0.001 & 1.23 & $(1.11-1.36)$ & 0.001 \\
\hline \multicolumn{7}{|l|}{ Age } \\
\hline $18-39$ years & Ref. & & & Ref. & & \\
\hline $40-59$ years & 1.91 & $(1.56-2.34)$ & 0.001 & 1.84 & $(1.54-2.21)$ & 0.001 \\
\hline$\geq 60$ years & 3.10 & $(2.42-3.98)$ & 0.001 & 2.99 & $(2.38-3.77)$ & 0.001 \\
\hline \multicolumn{7}{|l|}{ Severity } \\
\hline Non-life threatening illness & Ref. & & & Ref. & & \\
\hline Life-threatening illness & 1.07 & $(0.89-1.28)$ & 0.477 & 1.07 & $(0.92-1.24)$ & 0.395 \\
\hline \multicolumn{7}{|l|}{ Number of comorbidities } \\
\hline Without comorbidities & Ref. & & & Ref. & & \\
\hline 1 comorbidity & 1.21 & $(1.10-1.32)$ & 0.001 & 1.09 & $(1.01-1.18)$ & 0.024 \\
\hline 2 or more comorbidities & 1.24 & $(1.10-1.40)$ & 0.001 & 1.05 & $(0.94-1.16)$ & 0.365 \\
\hline \multicolumn{7}{|l|}{ Type of comorbidities } \\
\hline Obesity & 1.32 & $(1.10-1.58)$ & 0.003 & & & \\
\hline Cardiovascular diseases & 1.10 & $(0.94-1.28)$ & 0.226 & & & \\
\hline Hypertension & 1.12 & $(1.04-1.21)$ & 0.002 & & & \\
\hline Diabetes & 0.96 & $(0.89-1.03)$ & 0.208 & & & \\
\hline Chronic kidney disease & 1.38 & $(1.23-1.56)$ & 0.001 & & & \\
\hline Pulmonary disease & 1.01 & $(0.87-1.17)$ & 0.875 & & & \\
\hline Neoplasia & 1.13 & $(0.94-1.36)$ & 0.208 & & & \\
\hline Liver disease & 1.09 & $(0.79-1.50)$ & 0.604 & & & \\
\hline Rheumatic disease & 1.06 & $(0.68-1.64)$ & 0.795 & & & \\
\hline
\end{tabular}

* Cox regression with cluster variance estimation, using healthcare centers as clusters

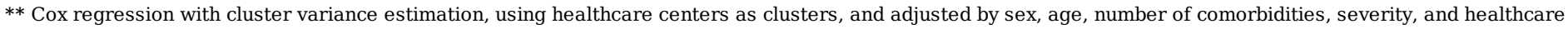
network (not shown).

Table 4. Crude and Adjusted Cox regression for in/out hospital mortality in patients hospitalized with confirmed COVID-19.

\begin{tabular}{|c|c|c|c|c|c|c|}
\hline \multirow[t]{2}{*}{ Variables } & \multicolumn{3}{|c|}{ Crude* } & \multicolumn{3}{|c|}{ Adjusted** } \\
\hline & cHR & $95 \% \mathrm{CI}$ & p-value & aHR & $95 \% \mathrm{CI}$ & p-value \\
\hline \multicolumn{7}{|l|}{ Sociodemographic variables } \\
\hline \multicolumn{7}{|l|}{ Sex } \\
\hline Female & Ref. & & & Ref. & & \\
\hline Male & 1.36 & $(1.22-1.52)$ & 0.001 & 1.30 & $(1.18-1.42)$ & 0.001 \\
\hline \multicolumn{7}{|l|}{ Age } \\
\hline 18 - 39 years & Ref. & & & Ref. & & \\
\hline 40 - 59 years & 3.91 & $(2.97-5.15)$ & 0.001 & 3.48 & $(2.73-4.44)$ & 0.001 \\
\hline$\geq 60$ years & 10.39 & $(7.50-14.39)$ & 0.001 & 9.21 & $(7.00-12.12)$ & 0.001 \\
\hline \multicolumn{7}{|l|}{ Severity } \\
\hline Non-life threatening illness & Ref. & & & Ref. & & \\
\hline Life-threatening illness & 1.34 & $(1.09-1.65)$ & 0.005 & 1.36 & $(1.16-1.59)$ & 0.001 \\
\hline \multicolumn{7}{|l|}{ Number of comorbidities } \\
\hline Without comorbidities & Ref. & & & Ref. & & \\
\hline 1 comorbidity & 1.44 & $(1.26-1.66)$ & 0.001 & 1.16 & $(1.04-1.31)$ & 0.010 \\
\hline 2 or more comorbidities & 1.56 & $(1.34-1.82)$ & 0.001 & 1.13 & $(1.01-1.26)$ & 0.031 \\
\hline \multicolumn{7}{|l|}{ Type of comorbidities } \\
\hline Obesity & 1.11 & $(0.92-1.34)$ & 0.260 & & & \\
\hline Cardiovascular diseases & 1.31 & $(1.09-1.58)$ & 0.005 & & & \\
\hline Hypertension & 1.40 & $(1.25-1.56)$ & 0.001 & & & \\
\hline Diabetes & 1.10 & $(1.02-1.19)$ & 0.013 & & & \\
\hline Chronic kidney disease & 1.88 & $(1.67-2.11)$ & 0.001 & & & \\
\hline Pulmonary disease & 0.99 & $(0.81-1.21)$ & 0.892 & & & \\
\hline Neoplasia & 1.52 & $(1.32-1.76)$ & 0.001 & & & \\
\hline Liver disease & 1.52 & $(1.07-2.16)$ & 0.018 & & & \\
\hline Rheumatic disease & 1.03 & $(0.68-1.57)$ & 0.897 & & & \\
\hline
\end{tabular}

* Cox regression with cluster variance estimation, using healthcare centers as clusters

** Cox regression with cluster variance estimation, using healthcare centers as clusters, and adjusted by sex, age, number of comorbidities, severity, and healthcare network (not shown). 
Figures

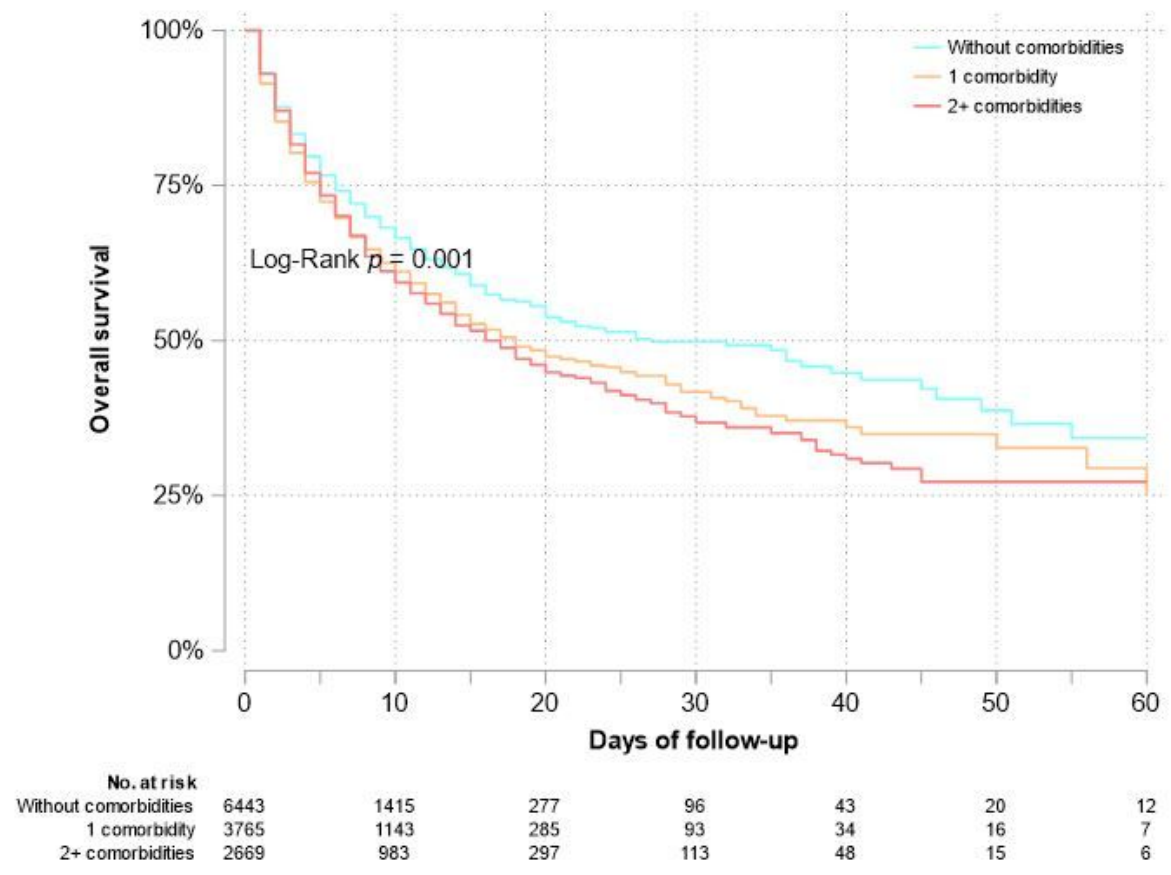

Figure 1

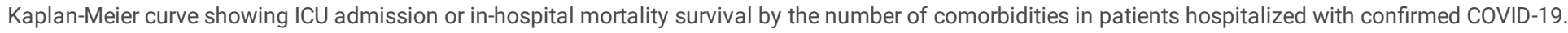

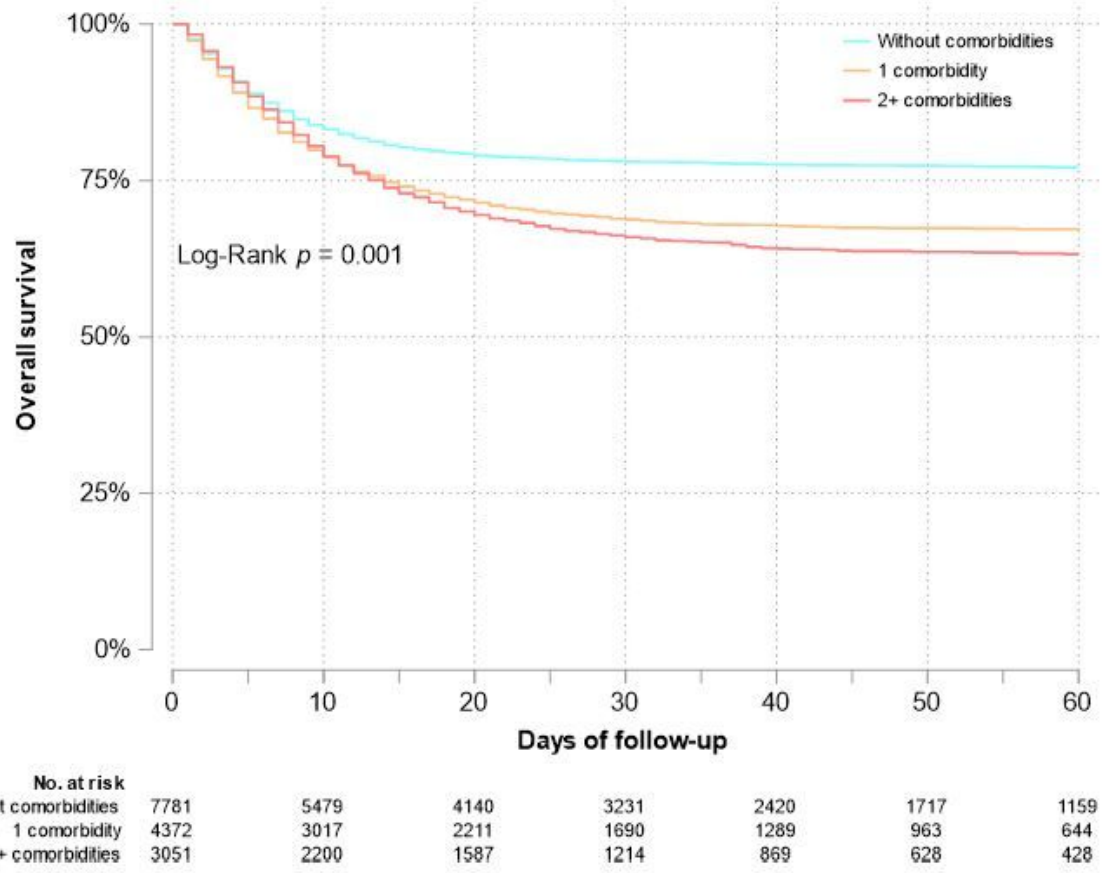

\section{Figure 2}

Kaplan-Meier curve showing in/out hospital survival by the number of comorbidities in patients hospitalized with confirmed COVID-19. 


\section{Supplementary Files}

This is a list of supplementary files associated with this preprint. Click to download.

- SUPPLEMENTARYTABLES.docx 